\title{
Naturally occurring reoviruses for human cancer therapy
}

\author{
Manbok Kim ${ }^{*}$ \\ Department of Medical Science, Dankook University College of Medicine, Cheonan 31116, Korea
}

\begin{abstract}
Naturally occurring reoviruses are live replication-proficient viruses that specifically infect human cancer cells while sparing their normal counterpart. Since the discovery of reoviruses in 1950s, they have shown various degrees of safety and efficacy in pre-clinical or clinical applications for human anti-cancer therapeutics. I have recently discovered that cellular tumor suppressor genes are also important in determining reoviral tropism. Carcinogenesis is a multi-step process involving the accumulation of both oncogene and tumor suppressor gene abnormalities. Reovinuses can exploit abnormal cellular tumor suppressor signaling for their oncolytic specificity and efficacy. Many tumor suppressor genes such as p53, ataxia telangiectasia mutated (ATM), and retinoblastoma associated (RB) are known to play important roles in genomic fidelity/maintenance. Thus, a tumor suppressor gene abnormality could affect host genomic integrity and likely disrupt intact antiviral networks due to the accumulation of genetic defects which in turn could result in oncolytic reovirus susceptibility. This review outlines the discovery of oncolytic reovirus strains, recent progresses in elucidating the molecular connection between oncogene/tumor suppressor gene abnormalities and reoviral oncotropism, and their clinical implications. Future directions in the utility of reovirus virotherapy is also proposed in this review. [BMB Reports 2015; 48(8): 454-460]
\end{abstract}

\section{INTRODUCTION}

Previously, I and others have stated that "Oncolytic viruses are live replication-proficient viruses that preferentially infect human cancer cells while sparing their normal counterparts. Replicating oncolytic viruses are quite different from conventional gene therapy viral vectors in several aspects. First, oncolytic viruses do not compromise their replication potential while viral vector genomes are severely modified to achieve non-replicating nature in gene therapy viral vectors. Second,

${ }^{*}$ Corresponding author. Tel: +82-41-550-3093; Fax: +82-41-5656167; E-mail: manbok66@dankook.ac.kr

http://dx.doi.org/10.5483/BMBRep.2015.48.8.076

Received 20 April 2015, Revised 20 May 2015, Accepted 3 June 2015

Keywords: Attenuated reovirus, Oncogene, Oncolytic virus, Reovirus, Tumor suppressor gene oncolytic viruses sometimes undergo replication competent-viral attenuation resulting in reduction of their natural pathogenicity while gene therapy vectors do not need viral attenuation since viral vectors are already replication-incompetent during the process of vector construction. Lastly, oncolytic viruses can contain a foreign gene, which can be expressed, in their viral genome, retaining viral replication potential while when gene therapy vectors contain a foreign gene which should be expressed in their viral genome, they have the complete lack of replication potency" (1).

Due to the unique features regarding the replicating nature of oncolytic viruses, they are highly dependent on the physiology of host cell for optimal performance as viral cancer-targeting agents. Many naturally occurring viruses have shown great potential as cancer-targeting agents by exploiting various oncogene signaling pathways established by host cancer cells during tumorigenesis (1-4). However, carcinogenesis is a multi-step process involving the accumulation of not only oncogene abnormalities but also the accumulation of tumor suppressor gene abnormalities. We have discovered that cellular tumor suppressor genes such as p53, ATM, and RB are also important in determining oncolytic viral tropism including reoviruses (5). Thus, an important mechanism of reoviral oncolysis can be established by both cellular oncogene and tumor suppressor gene abnormalities. Since the discovery of reoviruses in the 1950s, replicating reoviruses have shown various degrees of safety and efficacy in pre-clinical and clinical applications for human anti-cancer therapeutics. Here I provide a review on the recent progresses in molecular studies and preclinical/clinical aspects of reovirus oncolytic tropism.

\section{THE ORIGIN OF ONCOLYTIC REOVIRUSES}

Reoviruses belonging to Reoviridae family are ubiquitous and non-enveloped viruses containing 10 segments of double-stranded RNA (dsRNA) in their genome. Reoviruses are ubiquitous viruses isolated from various sources, including humans and water as well as sewage (6). There are three serotypes of reoviruses based on their hemagglutination activities. The prototypical laboratory strains of each serotype isolated from children's respiratory and enteric tracts are designated as Type 1 Lang, Type 2 Jones, and Type 3 Dearing (7). Reoviruses as acronym for respiratory enteric orphan virus coined by Sabin in 1959 were initially discovered in 1953 by Stanley et al. in Australia $(8,9)$. At the time, the worldwide poliovirus

ISSN: 1976-670X (electronic edition)

Copyright (c) 2015 by the The Korean Society for Biochemistry and Molecular Biology

(c) This is an open-access article distributed under the terms of the Creative Commons Attribution Non-Commercial License (http://creativecommons.org/licenses/by-nc/4.0) which permits unrestricted non-commercial use, distribution, and reproduction in any medium, provided the original work is properly cited. 
epidemic was widespread and poliovaccine development efforts were highly active around the world. During polio research in Australia, Stanley et al. isolated a virus from a fecal specimen of an aboriginal child resident at Yarra Bay Aboriginal settlement in Sydney. This virus uniquely caused an oily hair effect, encephalomyelitis, and other viral diseases in newborn mice experiments. Therefore, it was initially termed hepatoencephalomyelitis virus (8). However, eight years later, Stanley reassigned the name of hepatoencephalomyelitis virus to reovirus type 3 according to Sabin's proposed name scheme $(9,10)$. During polio research in the US, Ramos-Alavarez et al. (11) also isolated previously unknown viruses from stool specimen of healthy children in Cincinnati, Ohio. One of the unknown viruses isolated from a stool specimen of a healthy child living in Cincinnati later turned out to be the naturally occurring reovirus type 3 Dearing strain. This reovirus type 3 Dearing stain is currently used as a naturally occurring oncolytic virus for various preclinical and clinical trials (12).

\section{REOVIRUS AND SUBCLINICAL HUMAN DISEASES}

Due to their generally non-pathogenic nature, reoviruses were designated as orphan viruses (9). Although reoviruses have been recovered mostly from children having a variety of mild illnesses such as common cold and diarrhea $(8,13,14)$, they are also recovered from healthy people (15). Direct inoculation of reoviruses into human volunteers did not cause any significant human diseases $(16,17)$. Although a few volunteers developed mild afebrile illness, these illness could not be definitively attributed to the viruses inoculated during the human trial (16). In 2008, a phase I clinical trial of a reovirus showed a mild illness in a few patients (17). Direct inoculation of reovirus into humans causes asymptomatic or subclinical illnesses (Table 1).

\section{EARLY STUDIES OF THE ONCOLYTIC NATURE OF REOVIRUSES}

In 1960s, Bennette (18) was able to isolate an ascite tumor-destroying virus during the passage of ascite tumors in mice. It was serially transmissible and seemingly non-pathogenic in host mouse in the absence of neoplastic cells. Filtrates of ascitic fluids and extracts of cells harboring the unknown virus were highly destructive to Ehrlich carcinoma and other ascite tumors $(18,19)$. The unknown oncolytic virus isolated from the mouse ascite tumors was later identified as a strain of reovirus type $3 \mathrm{MH}$ (Middlesex Hospital) (20). In 1977, Harshiro et al. examined the oncolytic nature of the reovirus and showed that the reovirus type 2 D5 Jones strain preferentially induced cytotoxicity in certain transformed cells compared to its normal counterparts (21). In 1978, Duncan et al. also showed that the reovirus type 3 Dearing strain exerted a differential sensitivity between normal cells and SV-40-transformed cells. SV-40-transformed Wl-38 cells were highly susceptible to the cytotoxic potential of reovirus type 3 Dearing strain challenge (22). Many early studies indicated that the naturally occurring reoviruses somehow exerted innate oncolytic potential. However, the underlying molecular mechanisms of

Table 1. Disease outcome of direct inoculation of reoviruses into human

\begin{tabular}{|c|c|c|c|c|}
\hline & Reoviruses & \multirow{2}{*}{ Human tested } & \multirow{2}{*}{ Disease outcome } & \multirow{2}{*}{ Ref } \\
\hline Serotype & Inoculum doses $\left(\mathrm{TCID}_{50}\right)$ & & & \\
\hline Type 1 & $2 \times 10^{7.0}$ to $10^{7.5}$ & 9 volunteers & 3 volunteers become ill in a short term & Rosen et al., 1963 (16) \\
\hline Type 2 & $2 \times 10^{6.0}$ to $10^{6.5}$ & 9 volunteers & 3 volunteers become ill in a short term & Rosen et al., 1963 (16) \\
\hline \multirow[t]{2}{*}{ Type 3} & $2 \times 10^{7.5}$ to $10^{7.7}$ & 9 volunteers & 2 volunteers become ill in a short term & Rosen et al., 1963 (16) \\
\hline & $1 \times 10^{8.0}$ to $3 \times 10^{10.0}$ & 33 patients & 9 patients become ill (Grade 3-4) in a short term & Vidal et al., 2008 (17) \\
\hline
\end{tabular}

Table 2. Early studies of oncolytic reoviruses (from 1960s to 1970s)

\begin{tabular}{|c|c|c|c|c|}
\hline \multicolumn{2}{|c|}{ Reoviruses } & \multicolumn{2}{|c|}{ Comparison of viral tropism } & \multirow{2}{*}{ Ref } \\
\hline Serotype & Strain & Normal (Low susceptibility) & Transformed (High susceptibility) & \\
\hline Type 1 & ND* & & & \\
\hline Type 2 & D5 Jones & $\begin{array}{l}\text { Normal human diploid cell lines, } \\
\text { primary and continuous cell lines }\end{array}$ & $\begin{array}{l}\text { Virally and spontaneously } \\
\text { transformed cell lines }\end{array}$ & Harshiro et al., 1977 (21) \\
\hline \multirow[t]{2}{*}{ Type 3} & $\mathrm{MH}$ & Normal mouse host & Ascites tumor bearing mouses & $\begin{array}{l}\text { Bennette } 1960 \text { (18); } \\
\text { John et al., } 1960 \text { (19) }\end{array}$ \\
\hline & Dearing & WI-38 cells & SV-40 transformed WI-38 cells & Duncan et al., 1978 (22) \\
\hline
\end{tabular}

*Not done. 
reoviral oncolysis were not well understood until the 1990s. Early studies of oncolytic reoviruses are summarized in Table 2.

\section{MECHANISM OF THE ONCOLYTIC NATURE OF REOVIRUSES}

In 1998, the mechanistic aspects of reovirus' oncolytic nature was intensively studied by Lee's lab at the University of Calgary, Canada. Strong et al. were able to show that virally resistant NIH 3T3 cells became susceptible to reovirus type 3 Dearing challenge when the NIH 3T3 cells were intentionally transformed with activated Sos or Ras. Ras oncogene-transformed cells showed a compromised antiviral PKR activity compared to untransformed cells (23). Coffey et al. also showed that v-erbB-transformed NIH 3T3 xenografts were highly susceptible to reovirus type 3 Dearing challenge in a tumor bearing mouse model (24). When virally resistant cells had highly expressed cMyc oncogene, reovirus type 3 Dearing could preferentially infect them and induce cell death (25). cMyc proto-oncogene plays an important role in genomic maintenance. Deregulated expression of cMyc generates genomic instability (26-28). Oncogenes such as Ras and cMyc were initially thought to be oncogenic solely because of their role in proliferative control. However, recent studies have proposed that chromosome instability caused by the combined dysfunctional effects of oncogenes and tumor suppressor genes may be more central to tumorigenesis than previously thought

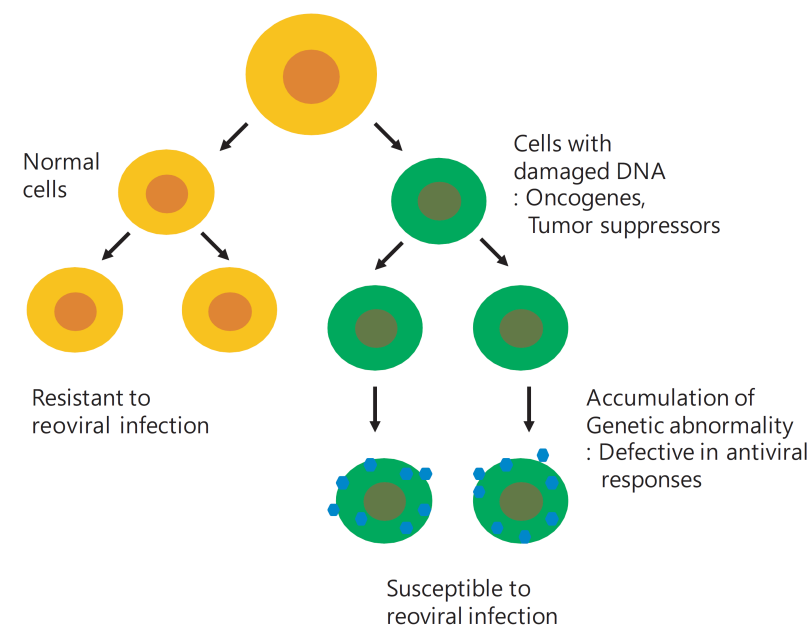

Fig. 1. Mechanistic basis of reovirus oncotropism. Carcinogenesis is a multi-step process involving the accumulation of cellular oncogenes and tumor suppressor gene abnormalities both genetically and/or functionally. Normal cells are resistant to reoviral infection due to intact anti-viral activity. However, tumor suppressor defective cancers have defects in genomic repair mechanisms. They could not preserve host genomic integrity upon genotoxic challenges, resulting in genomic instability and defective antiviral responses. Therefore, abnormal cancer cells can be preferentially infected by reoviruses due to the loss of intact anti-viral functionality.
(29). Thus, not only oncogenes but also tumor suppressor genes may play important roles in determining the oncolytic nature of reovirus since genomic instability could compromise the integrity of normal cellular anti-viral networks. In 2010, we showed that p53, ATM, and RB genes and their abnormal functions were important in determining reovirus oncolytic tropism. Abnormal functions of these tumor suppressor genes could render cells susceptible to reoviral challenges (5). I previously proposed that the abnormalities of tumor suppressor genes could increase genomic instability, which in turn could increases the occurrence of new mutations, including those affecting the antiviral-related host genes (1). Furthermore, genomic instability appears to be the engine of both tumor progression and stagnation of the normal function of antiviral-related cellular genes. Thus, reovirus oncolysis can be established mechanistically by both oncogenic hyper-activation and/or tumor suppressor abnormalities. The mechanistic basis of reovirus oncolysis regarding cellular oncogenes and tumor suppressor genes is shown in Fig. 1.

\section{RESISTANCE TO REOVIRAL ONCOLYSIS}

Innate or acquired cell resistance to chemotherapy and molecularly targeted therapies is a major problem in current cancer research and drug development. The mechanisms of resistance to cytotoxic chemotherapeutics and molecular therapies in cancer cells share many features, such as alterations in the drug target, activation of prosurvival pathways, and ineffective induction of cell death (30). In 2007, we investigated whether Ras-transformed cancer cells could acquire resistance to reoviral oncolysis (31). We challenged human HT1080 fibrosarcoma cells carrying a Ras mutation by prolonged exposure to a reovirus, thereby yielding highly virus-resistant HTR1 cells. After these

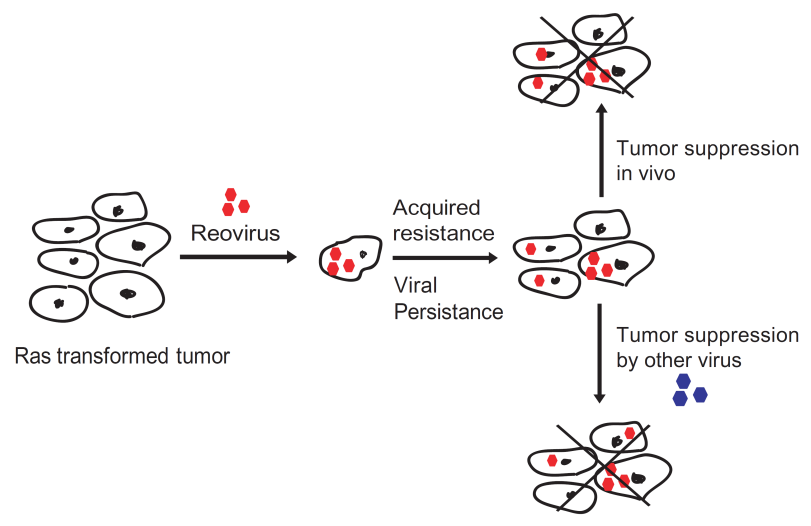

Fig. 2. Overview of resistance to reoviral oncolysis. Virally susceptible cancer cells could develop resistance to reoviral challenge. The surviving resistant cells still retain reovirus in a low dose (31). However, a xenograft of the resistant cells did not develop tumors in SCID mice $(31,32)$, indicating that the acquired resistant cells are not bona fide resistant in vivo. Furthermore, the resistant cells can be infected upon other oncolytic virus challenges (31). 
cells were persistently infected with the reovirus, they exhibited high Ras activity and retained the original Ras gene mutation, demonstrating that resistance to the reovirus can be displayed in cells with active Ras. HTR1 cells also exhibited reduced cellular cathepsin B activity which normally contributes to viral entry and activation by proteolytic cleavage of internalized viral capsid. Surprisingly, the acquired-resistance cells were not tumorigenic at all in xenograft experiments, revealing that viral persistence in the resistant cells plays an important role in tumor suppression. However, the mechanism of tumor suppression is not fully understood yet (31). Importantly, the acquired-resistance cells were fully susceptible to other viruses such as wildtype adenovirus or E1B defective adenovirus, demonstrating that reovirally resistant tumors can be challenged with other oncolytic viruses to enhance their overall viral oncolytic potency (31). We also used Burkitt's lymphoma cell line
Raji to establish reovirally resistant cells (32). These cells were again persistently infected but not tumorigenic in xenograft experiments. Interestingly, anti-serum-mediated cured resistant cells were still susceptible to reovirus re-challenge in xenograft experiments, indicating that the establishment of reovirus resistance is not strong enough to fully compromise reoviral oncolytic tropism $(31,32)$. These observations strongly suggest that repeated and/or combinatorial viral challenges could be beneficial to overcome cancer cell resistance during oncolytic viral therapies. An overview of resistance to reoviral oncolysis is shown in Fig. 2.

\section{ATTENUATED REOVIRUS FOR CANCER THERAPY}

Naturally occurring reoviruses harboring innate oncolytic potential are generally asymptomatic. Sometimes they cause only

Table 3. Summary of clinical trials with completed and ongoing using reovirus type 3 Dearing strain alone or in combination with other therapies

\begin{tabular}{|c|c|c|c|c|c|c|c|}
\hline Tumor types & Trial location & Phase & $\begin{array}{l}\text { Highest doses } \\
\left(\mathrm{TCID}_{50}\right)\end{array}$ & Safety/Efficacy & $\begin{array}{l}\text { ClinicalTrials. } \\
\text { gov identifier }\end{array}$ & Current status* & Ref \\
\hline \multirow[t]{2}{*}{ Brain cancer } & US & 1 & $10^{10}$ & Well tolerated & NCT00528684 & $\begin{array}{l}\text { Completed about } \\
2010\end{array}$ & \multirow{15}{*}{$\begin{array}{l}\text { Kicielinski et al., } \\
2014(48) \\
\text { Forsyth et al., } \\
2008(43)\end{array}$} \\
\hline & Canada & $1 / 2$ & $10^{9}$ & Well tolerated & & $\begin{array}{l}\text { Completed about } \\
2006\end{array}$ & \\
\hline \multirow{2}{*}{$\begin{array}{l}\text { Gynecologic } \\
\text { cancer }\end{array}$} & US & 2 & $10^{10}$ & & NCT01199263 & Active, not recruiting & \\
\hline & US & 1 & $10^{10}$ & & NCT00602277 & Active, not recruiting & \\
\hline \multirow[t]{2}{*}{ Colorectal cancer } & Canada & 2 & $10^{10}$ & & NCT01622543 & Recruiting & \\
\hline & US & 1 & $10^{10}$ & & NCT01274624 & Recruiting & \\
\hline Breast cancer & Canada & 2 & $10^{10}$ & & NCT01656538 & Recruiting & \\
\hline Prostate cancer & Canada & 2 & $10^{10}$ & & NCT01619813 & Recruiting & \\
\hline \multirow[t]{2}{*}{ Pancreatic cancer } & US & 2 & $10^{10}$ & & NCT01280058 & Active, not recruiting & \\
\hline & US & 2 & $10^{10}$ & & NCT00998322 & $\begin{array}{l}\text { Unknown, completed } \\
\text { about } 2014\end{array}$ & \\
\hline \multirow[t]{3}{*}{ Lung cancer } & Canada & 2 & $10^{10}$ & & NCT01708993 & Recruiting & \\
\hline & US & 2 & $10^{10}$ & & NCT00861627 & Active, not recruiting & \\
\hline & US & 2 & $10^{10}$ & & NCT00998192 & Active, not recruiting & \\
\hline \multirow{3}{*}{$\begin{array}{l}\text { Head and neck } \\
\text { cancer }\end{array}$} & $\begin{array}{l}\text { US, UK, Canada, } \\
\text { Belgium, etc }\end{array}$ & 3 & $10^{10}$ & $\begin{array}{l}\text { Well tolerated/ } \\
\text { limited efficacy }\end{array}$ & NCT01166542 & Completed in 2014 & \\
\hline & US & 2 & $10^{10}$ & & NCT00753038 & Completed in 2013 & \\
\hline & UK & $1 / 2$ & $10^{10}$ & $\begin{array}{l}\text { Well tolerated/ } \\
\text { limited efficacy }\end{array}$ & & Completed about 2012 & $\begin{array}{l}\text { Karapanagiotou } \\
\text { et al., } 2012(44)\end{array}$ \\
\hline \multirow{2}{*}{$\begin{array}{l}\text { Bone and soft } \\
\text { tissue Sarcomas }\end{array}$} & US & 2 & $10^{10}$ & & NCT00503295 & Completed about 2011 & \\
\hline & US & 2 & $10^{10}$ & $\begin{array}{l}\text { Well tolerated/ } \\
\text { limited efficacy }\end{array}$ & NCT00651157 & Completed in 2012 & Galanis et al., \\
\hline Skin cancer & US & 2 & $10^{10}$ & & NCT00984464 & Completed in 2014 & \\
\hline Hematological & US & Pilot & $10^{10}$ & & NCT02101944 & Recruiting & \\
\hline cancer & US & 1 & $10^{10}$ & & NCT01533194 & Active, not recruiting & \\
\hline $\begin{array}{l}\text { Childhood solid } \\
\text { tumors }\end{array}$ & US, Canada & 1 & $10^{10}$ & & NCT01240538 & Completed about 2014 & \\
\hline \multirow[t]{5}{*}{$\begin{array}{l}\text { Advanced solid } \\
\text { tumors }\end{array}$} & Canada & 1 & $10^{10}$ & $\begin{array}{l}\text { Well tolerated/ } \\
\text { limited efficacy }\end{array}$ & & Completed about 2002 & $\begin{array}{l}\text { Morris et al., } \\
2013(46)\end{array}$ \\
\hline & UK & 1 & $10^{10}$ & & & Completed about 2007 & Harrington et al., \\
\hline & UK & 1 & $10^{10}$ & & & Completed about 2007 & $\begin{array}{l}\text { Vidal et al., } \\
2008 \text { (17) }\end{array}$ \\
\hline & UK & 1 & $10^{10}$ & & & Completed about 2008 & $\begin{array}{l}\text { Comins et al., } \\
2010 \text { (37) }\end{array}$ \\
\hline & UK & 1 & $10^{10}$ & & & Completed about 2007 & $\begin{array}{l}\text { Lolkema et al., } \\
2011 \text { (36) }\end{array}$ \\
\hline
\end{tabular}

*As of May 2015. 
mild symptoms in immunocompetent humans. However, immunocompromised animal studies have shown considerable viral symptoms such as oily hair effect, myocarditis, black feet syndrome, and others $(20,31,33)$. Because cancer patients sometimes undergo severe immunosuppression due to the heavy chemo/radiation treatments or advanced tumor progression, this pathogenic nature in immunocompromised hosts could be a hurdle in wild type reovirus-based anticancer therapeutics. In 2007, we were able to isolate a genetically attenuated reovirus variant derived from persistently infected cells. The naturally attenuated reovirus was able to exert a potent anti-tumor activity while reducing viral pathogenesis in immunocompromised animal models $(31,34)$. The attenuated reovirus maintained its viral oncolytic potency in colon tumor xenograft experiments using SCID mice $(31,34)$. More importantly, the attenuated reovirus does not affect the integrity of murine embroyonic stem cells in vitro or in vivo (34). Thus, the attenuated reovirus could be used in pregnant patients to treat cancer. Although the efficacy of the attenuated reovirus is not thoroughly compared to wild type reoviruses, it could be used in cases where wild type reoviruses could not be applied due to unwanted side effects for particular cancer patients in a clinical setting.

\section{GENOMIC STABILITY OF REOVIRUSES}

Reovirus is a double-stranded RNA virus. Although RNA viruses are known to exhibit high rates of mutational change under a variety of conditions, we were able to show that no significant reovirus RNA genomic changes occurred during persistently infected cultures derived from various cell lines (32, 34). In the case of the attenuated reovirus derived from HTR1 culture, the attenuated viral genome could be maintained over three years (34). Thus, reovirus RNA genomes could be maintained in a stable manner during repeated infection in persistently infected cells $(31,34)$.

\section{HUMAN CLINICAL TRIALS}

The wild type reovirus type 3 Dearing strain is currently under-
(A)

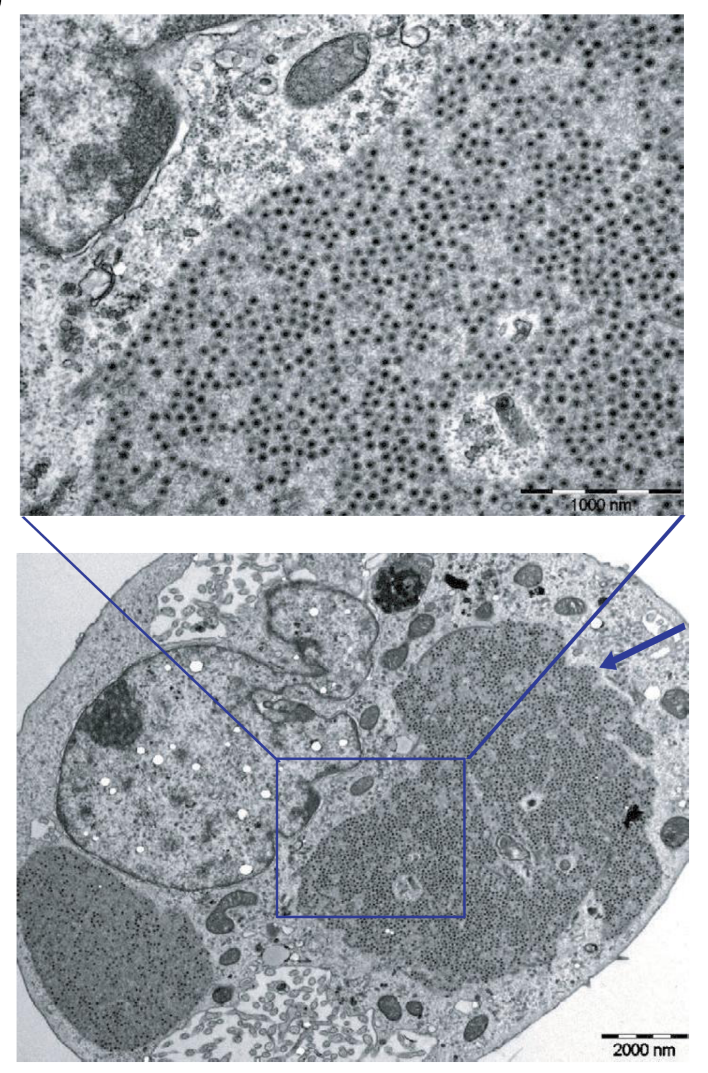

(B)

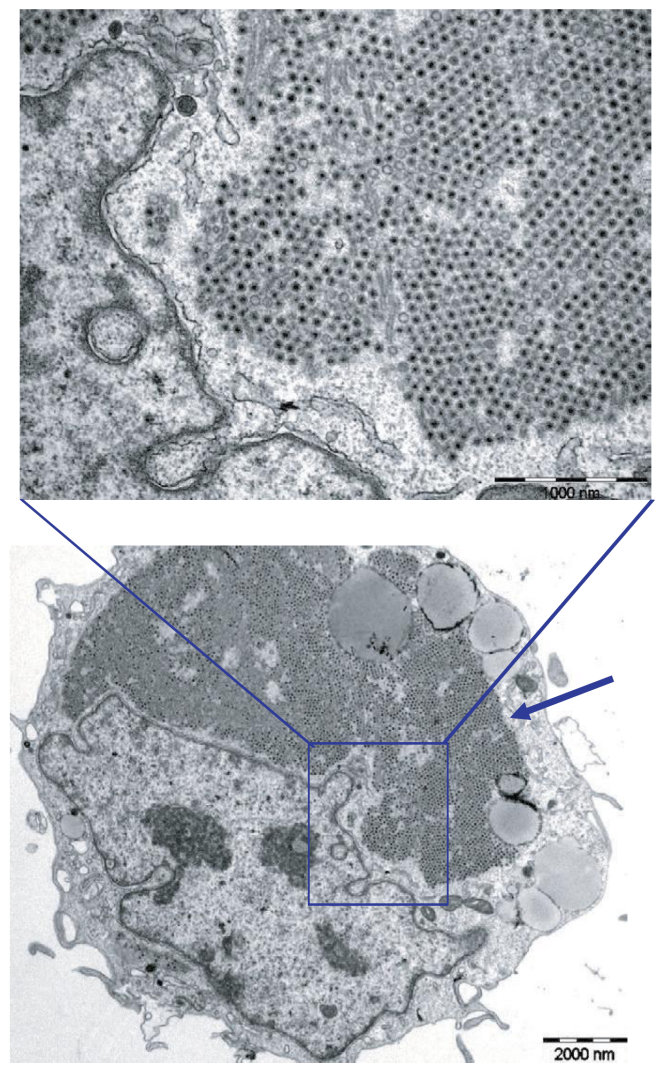

Fig. 3. Reoviral oncolytic tropism in hepatocellular carcinoma. Wild type reovirus type 3 Dearing strain (A) or attenuated reovirus type 3 Dearing strain viral particles (B) are detected in the cytoplasmic area of Hep3B human liver cancer cell upon reoviral challenges at 2-3 days post-infection $(10 \mathrm{MOI})$. Arrow indicates reoviral factory (lower panel). Mature/immature reoviral particles are shown in higher power electron microscope (EM, upper panel). EM magnification: 8,000× (lower panel), 30,000× (upper panel). 
going human clinical evaluations to treat various cancers (Table 3). Most clinical trials are conducted in the US and Canada. Since the Chinese government recently approved the use of reoviruses for human cancer therapy to target tumor suppressor-dysfunctional tumors $(5,35)$, a different patent profile from the previously approved reovirus patents for human cancer therapy that could target Ras-oncogenic tumors is established (23). Thus, our group is preparing clinical applications of oncolytic reoviruses for Asian countries. One of the reasons that reovirus can have two different patent profiles is due to the fact that the oncolytic nature of reovirus is already published from various investigators in the past. The mechanisms of reovirus oncolysis have not been identified until recently.

\section{FUTURE DIRECTIONS}

Since the discovery of reoviruses in 1950s, the oncolytic nature of several reovirus strains have been identified. During the past 15 years of molecular studies, the involvement of cellular oncogenes and tumor suppressor genes in determining reoviral oncolytic tropism is now fairly well established. Current clinical trials are mostly conducted in the US and Canada using reovirus type 3 Dearing strain. The safety aspects of reovirus type 3 Dearing have been strongly confirmed through many trials that have been conducted, although a few trials have shown limited human pathogenesis when reovirus was combined with immuosuppressive drugs $(36,37)$. As mentioned previously, the use of the attenuated reovirus could be an alternative strategy to reduce these potential risks. The attenuated reovirus could also be used for pregnant cancer patients due to the absence of pathogenicity in embryonic stem cells (34). As shown in Table 3, most clinical trials conducted or are being conducted are for human cancers highly prevalent in North America or Europe. In fact, gastric and liver cancers are among the most prevalent cancers in Asia and some other continents. Our study has shown that liver cancer cells are highly susceptible to the challenge of both wildtype reovirus type 3 Dearing and attenuated reovirus type 3 Dearing (Fig. 3). Thus, clinical application of reoviruses for liver cancers could be promising in the future. Oncolytic potency between serologically different reoviruses (type 1, 2, and 3) has not been well studied. Apparently, serotype differences do not show significant gap in oncolytic potency in vitro (38). If this is the case in in vivo environments, we might be able to combine them to overcome the innate/acquired immune resistance since the seropositivity of a particular strain has been documented to be as high as $70-100 \%$ in some studies $(39,40)$. Since the combinatorial oncolytic viral regimen could synergistically enhance oncolytic viral potency $(31,41,42)$, reoviruses could be used as a RNA oncolytic virus candidate in RNA plus DNA oncolytic viral combination strategy (42).

\section{DISCLOSURE}

M KIM is a scientific founder and shareholder of ViroCure which has replicating reovirus patents under clinical development.

\section{ACKNOWLEDGEMENTS}

The author's work is supported by a grant (NRF-2014R1A1 A2A16051067) of the Basic Science Research Program through the National Research Foundation of Korea (NRF) funded by the Ministry of Education, Science and Technology, Republic of Korea.

\section{REFERENCES}

1. Kim M (2015) Replicating poxviruses for human cancer therapy. J Microbiol 53, 209-218

2. Roberts MS, Lorence RM, Groene WS and Bamat MK (2006) Naturally oncolytic viruses. Curr Opin Mol Ther 8, 314-321

3. Wang G, Barrett JW, Stanford M et al (2006) Infection of human cancer cells with myxoma virus requires Akt activation via interaction with a viral ankyrin-repeat host range factor. Proc Natl Acad Sci U S A 103, 4640-4645

4. Strong JE, Coffey MC, Tang D, Sabinin P and Lee PW (1998) The molecular basis of viral oncolysis: usurpation of the Ras signaling pathway by reovirus. EMBO J 17, 3351-3362

5. Kim M, Williamson CT, Prudhomme J et al (2010) The viral tropism of two distinct oncolytic viruses, reovirus and myxoma virus, is modulated by cellular tumor suppressor gene status. Oncogene 29, 3990-3996

6. Tyler KL (2001) Mammalian reoviruses, p. 1729-1745. In B.N. Fields, D.M. Knipe, and P.M. Howley (eds), Fields Virology, Lippincott-Raven, Philadelphia, USA

7. Ramig RF, Cross RK, and Fields BN (1977) Genome RNAs and polypeptides of reovirus serotypes 1, 2, and 3. J Virol 22, 726-733

8. Stanley NF, Dorman DC and Ponsford J (1953) Studies on the pathogenesis of a hitherto undescribed virus (hepato-encephalomyelitis) producing unusual symptoms in suckling mice. Aust J Exp Biol Med Sci 31, 147-159

9. Sabin AB. Reoviruses (1959) A new group of respiratory and enteric viruses formerly classified as ECHO type 10 is described. Science 130, 1387-1389

10. Stanley NF (1961) Relationship of Hepatoencephalomyelitis Virus and Reoviruses. letters to Nature 189, 687

11. Ramos-Alvarez M and Sabin AB (1954) Characteristics of poliomyelitis and other enteric viruses recovered in tissue culture from healthy American children. Proc Soc Exp Biol Med 87, 655-661

12. Stoeckel J and Hay JG (2006) Drug evaluation: Reolysin--wild-type reovirus as a cancer therapeutics. Curr Opin Mol Ther 8, 249-260

13. Ramos-Alvarez $M$ and Sabin AB (1958) Enteropathogenic viruses and bacteria. Role in summer diarrheal diseases of infancy and early childhood. Jour Amer Med Ass'n 167, 147-156

14. Jackson GG, Muldoon BL and Cooper GS (1961) Reovirus type 1 as an etiologic agent of the common cold. Jour Clin Invest 40, 1051 
15. Ramos-Alvarez $M$ and Sabin AB (1956) Intestinal viral flora of healthy children demonstrable by monkey kidney tissue culture. Amer Jour Pub Health 46, 295-299

16. Rosen L, Evans HE and Spickard A (1963) Reovirus infections in human volunteers Am J Hyg 77, 29-37

17. Vidal L, Pandha HS, Yap TA et al (2008) A phase I study of intravenous oncolytic reovirus type 3 Dearing in patients with advanced cancer. Clin Cancer Res 14, 7127-7137

18. Bennette JG (1960) Isolation of a Non-pathogenic Tumour-destroying Virus from Mouse Ascites. Nature 187, $72-73$

19. Nelson JB and Tarnowski GS (1960) An Oncolytic Virus recovered from Swiss Mice during Passage of an Ascites Tumour. Nature 188, 866-867

20. Bennette JG, Bush PV and Steele RD (1967) Characteristics of a newborn runt disease induced by neonatal infection with an oncolytic strain of reovirus type 3 (REO3MH). I. Pathological investigations in rats and mice. Br J Exp Pathol 48, 251-266

21. Hashiro G, Loh PC and Yau JT (1977) The preferential cytotoxicity of reovirus for certain transformed cell lines. Arch Virol 54, 307-315

22. Duncan MR, Stanish SM and Cox DC (1978) Differential sensitivity of normal and transformed human cells to reovirus infection. J Virol 28, 444-449

23. Strong JE, Coffey MC, Tang D, Sabinin P and Lee PW (1998) The molecular basis of viral oncolysis: usurpation of the Ras signaling pathway by reovirus. EMBO J 17, 3351-3362

24. Coffey MC, Strong JE, Forsyth PA and Lee PW (1998) Reovirus therapy of tumors with activated Ras pathway. Science 282, 1332-1334

25. Kim M, Chung YH and Johnston RN (2007) Reovirus and tumor oncolysis. J Microbiol 45, 187-192

26. Kuttler F and Mai S (2006) c-Myc, Genomic Instability and Disease. Genome Dyn 1, 171-190

27. Prochownik EV and Li Y (2007) The ever expanding role for c-Myc in promoting genomic instability. Cell Cycle 6, 1024-1029

28. Prochownik EV (2008) c-Myc: linking transformation and genomic instability. Curr Mol Med 8, 446-458

29. Coschi $\mathrm{CH}$ and Dick FA (2012) Chromosome instability and deregulated proliferation: an unavoidable duo. Cell Mol Life Sci 69, 2009-2024

30. Holohan C, Van Schaeybroeck S, Longley DB and Johnston PG (2013) Cancer drug resistance: an evolving paradigm. Nat Rev Cancer 13, 714-726

31. Kim M, Egan C, Alain T et al (2007) Acquired resistance to reoviral oncolysis in Ras-transformed fibrosarcoma cells. Oncogene 26, 4124-4134

32. Alain T, Kim M, Johnston RN et al (2006) The oncolytic effect in vivo of reovirus on tumour cells that have survived reovirus cell killing in vitro. $\mathrm{Br}$ J Cancer 95, 1020-1027

33. Loken SD, Norman K, Hirasawa K, Nodwell M, Lester WM and Demetrick DJ (2004) Morbidity in immunosuppressed (SCID/NOD) mice treated with reovirus (dearing 3) as an anticancer biotherapeutics. Cancer Biol Ther 3, 734-738
34. Kim M, Garant KA, zur Nieden NI et al (2011) Attenuated reovirus displays oncolysis with reduced host toxicity. $\mathrm{Br}$ J Cancer 104, 290-299

35. Kim M and Johnston RN (2014) Tumor suppressor-based susceptibility of hyperproliferative cells to oncolytic viral therapy. Chinese patent No.: 200980126543.5 Date of Patent grant: July 30, 2014

36. Lolkema MP, Arkenau HT, Harrington K et al (2011) A phase I study of the combination of intravenous reovirus type 3 Dearing and gemcitabine in patients with advanced cancer. Clin Cancer Res 17, 581-588

37. Comins C, Spicer J, Protheroe A et al (2010) REO-10: a phase I study of intravenous reovirus and docetaxel in patients with advanced cancer. Clin Cancer Res 16, 5564-5572

38. Alloussi $\mathrm{SH}$, Alkassar $\mathrm{M}$, Urbschat $\mathrm{S}$, Graf $\mathrm{N}$ and Gärtner B (2011) All reovirus subtypes show oncolytic potential in primary cells of human high-grade glioma. Oncol Rep 26, 645-649

39. Minuk GY, Paul RW and Lee PW (1985) The prevalence of antibodies to reovirus type 3 in adults with idiopathic cholestatic liver disease. J Med Virol 16, 55-60

40. Minuk GY, Rascanin N, Paul RW, Lee PW, Buchan K and Kelly JK (1987) Reovirus type 3 infection in patients with primary biliary cirrhosis and primary sclerosing cholangitis. J Hepatol 5, 8-13

41. Le Boeuf F, Diallo JS, McCart JA et al (2010) Synergistic interaction between oncolytic viruses augments tumor killing. Mol Ther 18, 888-895

42. Alkassar M, Gärtner B, Roemer K et al (2011) The combined effects of oncolytic reovirus plus Newcastle disease virus and reovirus plus parvovirus on U87 and U373 cells in vitro and in vivo. J Neurooncol 104, 715-727

43. Forsyth P, Roldán G, George D et al (2008) A phase I trial of intratumoral administration of reovirus in patients with histologically confirmed recurrent malignant gliomas. Mol Ther 16, 627-632

44. Karapanagiotou EM, Roulstone V, Twigger K et al (2012) Phase I/II trial of carboplatin and paclitaxel chemotherapy in combination with intravenous oncolytic reovirus in patients with advanced malignancies. Clin Cancer Res 18, 2080-2089

45. Galanis E, Markovic SN, Suman VJ et al (2012) Phase II trial of intravenous administration of Reolysin( ${ }^{\circledR}$ ) (Reovirus Serotype-3-dearing Strain) in patients with metastatic melanoma. Mol Ther 20, 1998-2003

46. Morris DG, Feng X, DiFrancesco LM et al (2013) REO-001: A phase I trial of percutaneous intralesional administration of reovirus type 3 dearing (Reolysin ${ }^{\circledR}$ ) in patients with advanced solid tumors. Invest New Drugs 31, 696-706

47. Harrington KJ, Karapanagiotou EM, Roulstone $\mathrm{V}$ et al (2010) Two-stage phase I dose-escalation study of intratumoral reovirus type 3 dearing and palliative radiotherapy in patients with advanced cancers. Clin Cancer Res 16, 3067-3077

48. Kicielinski KP, Chiocca EA, Yu JS, Gill GM, Coffey M, Markert JM (2014) Phase 1 clinical trial of intratumoral reovirus infusion for the treatment of recurrent malignant gliomas in adults. Mol Ther 22, 1056-1062 